PREVENCIÓN CLÍNICA GUIA PARA MÉDICOS. Organización Panamericana de la Salud. Washington, DC: Organización Panamericana de la Salud, 1998.

ISBN 92-75-31568X

Prevención Clínica Guía para médicosé uma publicação científica organizada no Programa de Doenças não Transmissíveis da Organização Pan-Americana de Saúde/ OMS, cujo objetivo éfornecer subsídios para a elaboração e prática das políticas de prevenção das doenças não transmissíveis. O trabalho, publicado originalmente em espanhol, dirige-se aos países da América Latina, baseando-se no reconhecimento pela OPS da importância de tais agravos à saúde na morbi-mortalidade de suas respectivas populações. Reconhece, por exemplo, que “... actualmente, las enfermedades no transmisibles son responsables de más de $60 \%$ de las muertes y discapacidades en la Región. Afectam en particular a todos los adultos y no solo a los de edad avanzada. En América Latina y el Caribe, la primera causa de muerte en las mujeres de 15 a 64 años es el accidente cerebrovascular, seguido del infarto del miocardio, la diabetes y el cáncer del cuello del útero." (Prefácio p.vii).

O trabalho foi feito com base na seleção do material contido em The Canadian Guide to Clinical Preventive Health Care, do Grupo de Trabalho Canadense sobre o Exame Periódico de Saúde, grupo este que pertence ao Ministério Nacional de Saúde do Canadá, e cuja Divisão de Prevenção de Doenças Não Transmissíveis constitui-se em centro colaborador da OPS/OMS. A publicação teve seu material selecionado e revisado pela Dra. Sylvia C. Robles, que é assessora regional do programa na OPS.

É apresentado sob a forma de normas técnicas de prevenção clínica que visam facilitar as atividades de promoção à saúde. Logo de início, pode perceberse um dos marcos estratégicos, qual seja o de identificar no encontro do médico com o usuário do serviço o ponto privilegiado para a realização das ações preventivas. Isso pode parecer óbvio a uma primeira vista, portanto banal, mas logo mudamos de opinião quando percebemos que todo o trabal ho dirige-se para a construção de um discurso sobre determinado aspecto do fenômeno saúde-doença, que pretende ser legitimado pelas características de sua configuração. Neste sentido, a relação entre o profissional e o usuário do serviço faz parte da estrutura de tal discurso e, conseqüentemente, passa a ter que ser problematizada. É o ponto em que os diversos enunciados que dizem respeito às ações de promoção à saúde ganham crédito. Isso acontece em razão do fato de os profissionais, especialmente os médicos no momento da consulta, serem a fonte legítima de informações, não só sobre as enfermidades, mas também sobre os fatores de risco ao adoecimento. É a partir daí que o enunciado da medicina preventiva converte-se na prática de promover saúde para a população.

O grupo canadense parte desse princípio, alertando-nos, entretanto, para dois problemas que fazem parte da estrutura desse modelo, cujas soluções constituem o solo epistêmico do trabalho. Primeiro, destaca que as medidas oficiais de promoção à saúde nem sempre refletem uma síntese, ao menos razoável, do conhecimento a respeito do tema a que se dirigem. Depois, afirma que o próprio discurso fundador de tais normas freqüentemente afasta-se do racionalismo, referindo-se este último termo ao racionalismo crítico, isto é, ao conjunto de procedimentos que visam refletir sobre a legitimidade de determinados enunciados, confrontando-os com a realidade factual. Mas, como assumir isto sem rumar para o ideal da ciência positiva, que crê na existência de fatos em si, independentes das teorias?

A primeira parte do livro - Metodologia - vai ocupar-se dessa tarefa, definindo de forma muito clara um paradigma legitimador das prescrições de promoção à saúde relativas à profilaxia das doenças selecionadas. Em seguida, vai abordar a questão da validade de normas gerais, idealizadas no Canadá, em sua aplicação às múltiplas e específicas situações de cada região da América Latina, que é um problema não menos metodológico do que o primeiro, se é que é correto pensar no método como algo quantificável. O caminho escolhido é tão elegante quanto ousado, pois a adaptação da norma geral para uso nas situações cotidianas está longe de ser uma tarefa de simples obediência a uma prescrição. Efetivamente não é esta a opção que nos é apresentada. Aqui, toma-se a norma como enunciado a ser testado em cada situação específica, o que pode ser comparado ao conhecido problema de validação externa de um estudo, ganhando, entretanto, configuração tal, que perde de vista os limites entre lógica e ética na fundação de seu solo epistêmico. Assim, suscita-se que enunciados normativos sejam forjados nos locais de aplicação; a construção de tais enunciados valendo-se de situações de saúde e doença específicas, contingentes, é a própria condição de aplicabilidade das normas, ou seja, é a maneira eficaz de promover-se a saúde.

A segunda parte - Problemas específicos - encarrega-se da apresentação técnica de propostas de ações em prevenção primária e secundária para uma seleção de 18 problemas relativos aos agravos à saúde provocados por doenças não transmissíveis. Agora, podemos testemunhar a leveza da opção metodológica que, ao mesmo tempo em que se afasta da arrogância essencialista, não se deixa levar pela armadilha relativista. Em todas as passagens desta parte técnica do manual, o leitor pode perceber, ora de forma direta, ora menos explicitamente, o convite a tomar cada capítulo menos como uma fonte de informações inequívocas, do que como um exemplo de 
procedimentos a serem avaliados. O bom usuário desse instrumento apropria-se mais de seus processos, do que de seus resultados. Assim é que o pragmatismo metodológico desses capítulos técnicos chamam a atenção para uma face do exercício da ciência freqüentemente delegada ao campo exclusivo da moral. Trata-se da ética, que ganha significado epistêmico no experimento científico, uma vez que o conteúdo de verdade de cada enunciado prescritivo passa a ser modulado pela prática das ações em saúde, imbuídas, agora, de um estatuto experimental. Ética e lógica de pesquisa aqui se misturam, porque a noção de verdade, por ser contingente, perde seu caráter essencial, suscitando, contudo, critérios para firmar jurisprudência, por assim dizer, o que só pode ser feito na forma de um racionalismo que não seja dogmático. As normas passam a ser vistas como sistemas axiomáticos a serem postos à prova, aceitos, refutados ou modificados pela realidade factual, no caso, as especificidades de cada local em questão. As atividades de promoção à saúde têm o duplo papel de melhorar as condições de saúde da população-alvo, ao mesmo tempo em que, do ponto de vista metodológico, constituem-se em elementos testemunhais da legitimidade dos discursos normativos, o que obviamente vai implicar a eficiência e efetividade dos mesmos.

A técnica básica preconizada pelo grupo de trabalho canadense é a do exame periódico de saúde, isto é, a exploração periódica de saúde orientada para a prevenção, detecção e controle dos processos de risco dos distintos grupos (classificados por idade, sexo, etc.). É preconizada em substituição ao conhecido exame físico anual de rotina. Mais uma vez o grupo de trabalho dá demonstração de preocupação com a estrutura racional de seu modelo e percebe-se a opção metodológica que dá ao fenômeno do risco o estatuto de hipótese a ser validada nas populações a que se destinam as ações. Promover saúde de forma eficiente é elaborar e executar ações fundamentadas numa expectativa prévia que os promotores devem ter com relação aos agravos à saúde da população. 0 potencial empírico de um método que parte de expectativas com relação à Natureza é muito maior do que o daquele que simplesmente coloca observador em contato direto com a realidade bruta. Esta é a diferença existente entre a técnica preventivista baseada no exame periódico de saúde, orientada para o risco, e aquela do exame físico anual de rotina. É a opção pelo caminho que confronta um ente lógico, discurso prescritivo sobre saúde/ doença, e os entes factuais, processo real de adoecimento de uma certa população, dispensando-se o essencialismo em ambos os lados. É justamente na fronteira entre tais constructos que o conhecimento fundador das práticas de promoção à saúde adquire a sua legitimidade. É preciso que este espaço de tensão entre teoria e prática seja desenvolvido, sem o que haverá perda de conteúdo empírico dos discursos. Por isso, o grupo de trabalho descarta a possibilidade do exame físico anual de rotina, visto que, com ele, de forma isolada, perde-se muito da referida área de tensão, uma vez que as expectativas a priori constituem-se numas das dimensões do espaço de confronto.

Finalmente, as normas devem ser mutuamente compatíveis e o custo da implementação de cada uma deve ser compensado pelo benefício de melho- ria global da saúde dos indivíduos. Trata-se da exigência da efetividade como amálgama que dá integridade à estrutura epistemológica proposta. Mais uma vez podemos apreciar o quanto os idealizadores deste trabalho compreendem método como algo a ser progressivamente edificado. É claro que as exigências de compatibilidade e efetividade não são atendidas com base em critérios puramente matemáticos; novamente testemunhamos a importância dada pelo grupo de trabalho à totalidade da estrutura metodológica, no lugar de cometer o equívoco de transformar o que deveria ser um trabalho crítico, portanto epistêmico, numa tarefa de discussão de técnicas de pesquisa. Agora, os problemas lógicos, matemáticos e patológicos passam a ser ponderados pela noção de melhoria global da saúde, o que faz com que aquilo que é específico em cada situação adquira importância própria. Como incorporar tais contingências a uma proposta de método que obviamente não deve ser equívoca? Como fazer isto sem rumar para um anarquismo epistêmico, que inviabiliza qualquer possibilidade normativa?

Simplesmente tomando cuidado para não confundir as atividades de construção de hipóteses com as de edificação de toda a estrutura epistemológica da teoria sobre os agravos à saúde da população-alvo. Para construir as hipóteses, utilizam-se os dados da literatura, opinião de especialistas, conhecimentos de biologia, fisiopatologia de doenças, além de outras disciplinas, como a sociologia. Em seguida, parte-se para a montagem da teoria que pretenderá dar o fundamento científico às ações de prevenção. É nesse ponto que os pressupostos serão integrados numa rede axiomática, usando-se, para este fim, argumentos da lógica e da matemática, que tomam sentido no conjunto de técnicas da epidemiologia. $O$ impacto das ações na saúde da população servirá, por sua vez, de instrumento de validação da teoria. Em todas essas etapas, a atividade crítica é condição necessária, mas é especialmente na última, na validação do impacto das medidas, que a dimensão ética do método aparece com maior nitidez. É aqui que o fato empírico, embora construído, pode exercer o poder de avaliação da teoria que o gerou, fazendo com que o sistema constitua-se em algo sempre a ser lapidado. Isto é ético, democrático e racional.

Assim, o método divide-se em duas partes. A primeira visa à elaboração de normas para a prática clínica baseadas nas evidências obtidas das publicações médicas; a segunda diz respeito à avaliação da efetividade das intervenções preventivas e, como já assinalado, contribui também para o estado do conhecimento que dá origem às publicações científicas referidas.

Como destacado anteriormente, a primeira parte do livro vai ocupar-se da construção dos pressupostos ou dos axiomas que vão definir a estrutura do discurso racional sobre a prevenção clínica. As recomendações básicas virão da revisão da literatura médica de trabalhos que foram elaborados valendo-se de:

- ao menos um ensaio controlado, randomizado e bem desenhado;

- ensaios controlados, bem desenhados, mas não randomizados;

- estudos analíticos bem desenhados, de coorte e de caso-controle, executados preferencialmente em 
mais de um centro e por mais de um grupo de pesquisa;

- comparação entre momentos e lugares, com ou sem a intervenção;

- opinião de autoridades reconhecidas, baseada na experiência clínica, estudos descritivos ou informes de comitês de especialistas.

Tais critérios estão dispostos em ordem decrescente de valor empírico. A classificação das recomendações acompanha, então, a qualidade de tais agrupamentos da seguinte forma:

A: Existem provas sólidas para respaldar a recomendação de que o processo seja considerado (ou que não seja: E) especificamente como parte do exame periódico de saúde.

B: Existem provas razoáveis para respaldar a recomendação de que o processo seja (ou que não seja: D) considerado especificamente como parte do exame periódico de saúde.

C: Existem poucas provas referentes à inclusão do procedimento em um exame periódico de saúde, mas pode ser aconselhável a sua inclusão por outros motivos.

Os problemas específicos selecionados como objeto das ações em saúde, listados na segunda parte do livro, referem-se às doenças causadas pelo hábito de fumar, à detecção precoce dos cânceres do colo do útero, de mama, de próstata, à prevenção das lesões por acidente de tráfego, à detecção sistemática da hipertensão arterial, do diabetes mellitus, da obesidade, dentre outros agravos à saúde provocados por doenças não infecciosas.

O livro apresenta também um guia para a implementação das normas clínicas, cujo objetivo é subsidiar os planejadores e executores dos programas de cada região. Também é um documento aberto, isto é, seu uso irá implicar necessariamente modificações e adaptações nos locais de uso.

Em suma, trata-se de um manual de normas que curiosamente abre mão das prerrogativas de prescrição, rumo a uma função enunciativa. O que torna esse trabalho de certa forma fascinante é o fato de os organizadores da obra estarem plenamente conscientes de ser essa uma condição necessária ao sucesso na implementação das medidas de prevenção primária e secundária propostas.

Fernando Salgueiro Passos Telles Departamento de Epidemiologia

e Métodos Quantitativos em Saúde

Escola Nacional de Saúde Pública

Fundação Oswaldo Cruz

Rio de Janeiro, RJ, Brasil
A TERCEIRA MARGEM DA SAÚDE. Fermin Roland Schramm. Brasília: Editora UnB, 1996. 265 pp. ISBN 85-230-0385-1

O uso recorrente de determinadas palavras retirou delas a força ou, ao menos, o poder explicativo, tornando-se, quando muito, palavras de ordem ou bordões desprovidos de significado. Por conta disto, tenho relutado em usar termos como crise, modernidade ou até paradigma, mesmo quando estes são aparentemente inevitáveis.

Ainda assim, é forçoso reconhecer a emergência de uma nova configuração no campo dos saberes e práticas da saúde coletiva que, embora longe de um triunfo definitivo como às vezes parece crer-se, traz uma maior radicalização ao escopo da reflexão crítica nesse campo. Renunciando aos fundacionismos desde sempre presentes na formulação do campo quer pela vertente do materialismo dialético, quer pela da afirmação da positividade da biologia, ou, de modo mais genérico, do magister dixit científico - a própria raison d'etre do campo se torna motivo de reflexão crítica.

Dito de outra forma, se já não nos é possível afirmar que a saúde coletiva é uma necessidade histórica ou mera decorrência de aplicação de uma ratio canônica a mais um entre tantos problemas da vida cotidiana, como se justifica a necessidade de uma perspectiva coletiva na saúde? Que valores comuns (se é que existem) devem orientá-la?

Estas questões têm estado na pauta das discussões sobre o campo da saúde coletiva em nosso País de forma particularmente intensa nessa última década, sendo tema em um sem-número de publicações e apresentações em congressos e seminários. Desenhase, então, um retorno à ética, por vários caminhos, como a perspectiva de (re)fundação do próprio saber-fazer

Ainda que sem questionar propriamente o mérito desse tipo de formulação quase consensual, um exame mais acurado do ponto de vista filosófico traz um certo incômodo: não se estaria simplesmente contornando o enfrentamento do problema, retirando-se, num certo sentido, o proverbial sofá da sala? Não seria a delegação de toda a reflexão ao campo da ética mera renuncia à discussão, evocando involuntariamente o primeiro Wittgenstein (o que não posso falar, devo calar)? E por falar nisso, que 'ética', cara pálida?

É essa tarefa espinhosa que Schramm ataca em seu livro, o que torna igualmente espinhosa a tarefa de resenhá-lo. Dada a amplitude dos temas abordados, os autores recrutados por Schramm para seu diálogo (só o índice onomástico tem sete páginas), a variedade de abordagens empregada na discussão, corre-se o risco de a resenha tornar-se tão extensa quanto o livro em questão, o que, por si só, já fala de seus méritos. Correndo, portanto, o risco da simplificação excessiva, tentarei apontar os grandes traços do trabalho de Schramm, esperando não ser excessivamente grosseiro na tarefa.

Nas palavras do próprio autor, a pesquisa que fundamenta seu livro “(...) propõe-se a delinear aqueleque poderia ser definido como o 'universo discursivo de uma ética em saúde' ea discutir seus fundamentos filosófico-epistemológicos a partir deum ponto de vista 'laico', no contexto da paradigmologia das Ciências 
da Complexidade" (Introdução, página 11). Com efeito, esta declaração introdutória resume adequadamente o conteúdo do livro.

Em primeiro lugar, Schramm propõe uma ética natural para a saúde - advertindo que não deve ser confundida com uma ética naturalista -, tendo como base a discussão sobre a complexidade do campo, com ênfase na visão de Morin, propondo a síntese de princípios eventualmente tidos como antagônicos, o da qualidade e o da sacralidade da vida, apoiando-se em Ortega y Gasset, entre outros. É digna de nota a tentativa de aproximação de pontos de vista aparentemente díspares - de resto, um dos pontos fortes deste trabalho -, como os de Kant e Nietzsche, por exemplo.

Baseado nessa delimitação, o autor examina o campo da saúde coletiva, discutindo sobre o significado e a extensão da 'crise' e, por decorrência, sobre a própria definição do campo. Posteriormente, faz-se o exame do contexto filosófico desta crise, com uma recapitulação detalhada do debate sobre o relativismo e o pós-modernismo, situando adequadamente as dificuldades surgidas pela extensão de princípios relativistas ao campo da ética. Por fim, as várias tramas tecidas ao longo do texto são postas em conjunto no confronto entre as exigências concretas da saúde dos sujeitos e as possibilidades de uma ética natural tal como proposta pelo autor.

Há alguns pontos que mereceriam uma discussão um pouco mais apurada: por exemplo, ao contrário de Schramm (p. 116, nota 36), não vejo Burtt considerando negativamente as bases metafísicas do pensamento, e a revisão das conseqüências da discussão pós-moderna eventualmente faz uma simplificação algo excessiva dos autores criticados por Schramm. Por outro lado, dificilmente se conseguirá defender e expor uma tese sem incorrer nesse risco, ainda assim, creio que o último ponto em particular mereceria talvez uma ampliação de foco. Ao restringir-se ao debate filosófico num sentido estrito, Schramm prescindiu de autores - como Boaventura de Souza Santos, por exemplo - que fazem uma leitura bastante original dessa problemática, apontando rumos inovadores para as Ciências Sociais, com conseqüências também para nosso campo específico. Deixo aqui esse registro, possivelmente como desafio para Schramm abordar em seu próximo trabalho.

De qualquer forma, é um trabalho de referência, inovador e corajoso, que traz para a frente do debate uma questão fundamental convenientemente deixada em suspenso no campo da saúde coletiva. Espero que a intervenção de Schramm nessa discussão propicie o exame das questões éticas na saúde com o mesmo rigor que as cognitivo-epistemológicas vêm sendo tratadas.

Kenneth Rochel de Camargo Jr.

Instituto de Medicina Social

Universidade do Estado do Rio de Janeiro

Rio de Janeiro, RJ, Brasil
ENTRE INCERTEZAS E CONTRADIÇÕES. PRÁTICAS REPRODUTIVAS ENTRE MULHERES DAS COMUNIDADES ECLESIAIS DE BASE DA IGREJA CATÓ LICA. Lúcia Ribeiro e Solange Luçan. Rio de J aneiro: Nau Editora, 1997. 154 pp.

ISBN 85-85936-18-5

O livro publicado por Lúcia Ribeiro e Solange Luçan apresenta uma síntese dos resultados de uma pesquisa realizada com mulheres das Comunidades Eclesiais de Base (Cebs) de Nova I guaçu. As Cebs correspondem a uma experiência inovadora que vem sendo desenvolvida no âmbito católico. O objetivo do estudo foi conhecer as práticas sexuais e reprodutivas dessas mulheres, bem como os valores que as configuram e orientam. As autoras pretendiam verificar de que forma tais práticas e valores se articulavam com as normas estabelecidas pela doutrina da I greja Católica. A pesquisa foi desenvolvida na diocese de Nova I guaçu (no centro-sul do Estado do Rio de Janeiro), de abril de 1993 a março de 1995. Foram entrevistadas 265 mulheres que tinham uma efetiva atuação nas atividades das Cebs.

Na primeira parte do livro, as autoras situaram a sexualidade e a reprodução no processo de transformação sócio-cultural das últimas décadas e a forma como a I greja Católica e as Cebs se inserem nele. As autoras afirmam que, dentro da Igreja Católica, é possível distinguir pelo menos quatro tipos de discursos que expressam a doutrina moral: o da hierarquia, o teológico, o pastoral e o dos fiéis. Existem diferenças e coincidências entre os discursos e nenhum deles é estático. As Cebs são formadas por membros dos setores populares, expressam basicamente uma nova forma de ser Igreja e se caracterizam tanto pela integração entre o religioso e o social ('união de fé e vida'), quanto pelo compromisso com a transformação social. Sua vivência se baseia na participação dos leigos no apostolado hierárquico da I greja Católica, entretanto esta abertura não se aplica ao âmbito do social e reprodutivo, considerado parte da vida privada.

A participação das mulheres nas Cebs é expressivamente maior que a dos homens, sobretudo nas atividades organizadas pela própria comunidade, todavia sua participação é menor nos postos de direção.

Nos capítulos que seguem, são apresentados os resultados, primeiro sobre algumas características das mulheres (por exemplo, idade, escolaridade e estrutura familiar), bem como sobre suas práticas sexuais e reprodutivas. A seguir, apresenta-se a experiência de participação das mulheres nas Cebs e a forma como articulam seu conhecimento da doutrina eclesial com as práticas sexuais e reprodutivas. $\mathrm{Na}$ última parte, são apresentadas as conclusões. Como anexo, inclui-se uma breve descrição da metodologia e o questionário utilizado.

Em geral, os capítulos são cansativos de ler, pois incluem numerosos gráficos (56), em que freqüentemente não é possível identificar a percentagem que corresponde a cada legenda porque as cores se confundem. Também são apresentadas 25 tabelas com elementos que só poluem as mesmas, o que dificulta sua leitura e compreensão. Por exemplo, na Tabela 1, é desnecessária a palavra 'de' antes de cada categoria de idade, bem como o sinal de ‘\%'. O número de muIheres no total de cada coluna é tão pequeno, que não justifica a inclusão de valores decimais (por exemplo, 
$61,5 \%$ de 13 ou $66,7 \%$ de 3 não significa nada). Ao apresentar os resultados, as autoras comparam as Tabelas 1, 2 e 3 e falam de "mais si gnificativa”, sem, no entanto, haver nas tabelas alguma indicação do teste estatístico aplicado. Esse problema se repete ao longo dos dois capítulos sobre resultados.

Também dificulta a leitura das tabelas o nome de algumas variáveis independentes. Por exemplo, Faixa etária - I - anos (Tabela 1) e Faixa etária - II - anos (Tabela 4): não fica claro por que se usam diferentes categorias para idade (Tabelas 1 e 4) e escolaridade (Tabelas 3 e 14). Falta sistematização ao apresentar os dados, porque se fala de faixa etária (Tabela 1) e de classe de idade (Tabela 13). Na Tabela 10, também não fica claro o que significa "Idade da 1a união/Casamento por escolaridade".

Os títulos de vários gráficos ( 20 a 25, por exemplo) estão errados. A variável dependente é uso de anticoncepcionais, portanto determinada pelo número de filhos, escolaridade, etc. Por exemplo, o título correto da Tabela 20 é "Uso de métodos anticoncepci onais segundo número de filhos". A Tabela 13 é confusa: por que médias com tantos decimais (até quatro)?

Ao comentar o Gráfico 41, as autoras afirmam que "a mai or parte (45\%) das mulheres com experiências de aborto o aceita só em casos especiais". No entanto, esta é a maior porcentagem e não a maior parte (que seria mais da metade das mulheres).

Ao apresentar resultados sobre a relação com a I greja Católica, as tabelas mostram abreviaturas que não se entendem (por exemplo, Tabelas 22, 23, 24). Na página 101, fala-se de tipo de participação e tipo de mulheres (taxa ou grau), o que não está claro nas tabelas.

Ao analisar a porcentagem de mulheres com ligadura de trompas, segundo conhecimento da doutri$\mathrm{na}$, as autoras esquecem de considerar se, entre as esterilizadas, há um maior número de mulheres de mais idade, com mais filhos ou que tiveram parto por cesárea. Estas variáveis, e não simplesmente o fato de conhecer ou não a doutrina da I greja, (Gráfico 51) poderiam ser a explicação para o porquê de terem ligado as trompas. Não é esclarecido como foi construído o índice de conhecimento da doutrina (Gráfico 55).

Nas conclusões, espera-se que seja feita uma análise de seus resultados, baseando-se em um contexto no qual está inserida a amostra estudada, entretanto as autoras seguem apresentando resultados, discutindo, por exemplo, a questão da maternidade, o que não tinha sido apresentado antes.

O conhecimento de métodos anticoncepcionais não indica necessariamente uma preocupação explícita com a regulação da própria fecundidade. As possíveis fontes de informação são muitas, e as mulheres podem ter tido acesso a elas por acaso e não por terem procurado se informar.

As autoras apresentam mais análises do que o inicialmente proposto, incluindo comparações entre grupos, o que não faz parte dos objetivos do livro. Ao ler os resultados e parte da conclusão, tem-se a impressão de que foram realizadas entrevistas em profundidade, uma vez que as autoras apresentam uma análise de dados mais detal hada do que uma entrevista fechada consegue captar.

Resumindo, este poderia ter sido um livro interessante e esclarecedor. Infelizmente, a análise dos dados é confusa e às vezes errada. A apresentação dos resultados é cansativa de ler, as tabelas e gráficos são de má qualidade. As autoras não alcançaram seus objetivos.

\section{Ellen Hardy}

Departamento de Tocoginecologia

Universidade Estadual de Campinas

Campinas, SP, Brasil

NOBRES E ANJ OS: UM ESTUDO DE TÓXICOS E HIERARQUIA. Gilberto Velho, Rio de J aneiro: Fundação Getúlio Vargas, 1998. 216 pp.

ISBN 85-225-0239-0

Nobres e Anjos é a edição da tese de doutoramento de Gilberto Velho, defendida em 1975. Como o autor revela, é um estudo que busca ampliar o conhecimento das chamadas 'camadas médias' urbanas, proposta que já vinha construindo desde sua dissertação de mestrado, com o estudo dos white-collar copacabanenses. Nessa trajetória, elege como temática os estilos de vida e visões de mundo considerados pela sociedade como 'anormais' ou transgressores. Sua lente busca enfocar a relação entre 'camadas médias' e 'desvio'. Opta, assim, como estratégia de investigação, pelo universo do uso de tóxicos, definido como campo de vivências de ilegalidade e clandestinidade. Percebe-se, portanto, que, por motivos óbvios de segurança pessoal do autor e de seus informantes, tal estudo, escrito no auge da ditadura brasileira, precisou não ser publicado na época.

Velho trabalhará com dois grupos ao longo de dois anos (1972 a 1974). O primeiro, de adultos de 25 a 35 anos, e o segundo, de adolescentes de 13 a 25 anos. Questiona e relativiza, desde a introdução, em que medida o conceito de grupo realmente traduz alguma identidade e solidariedade entre seus membros (o que seria reconhecível num primeiro plano, pela construção de uma linguagem própria e um repertório de códigos, isto é, um “campo de comunicação e interação" peculiar). Na realidade, reconhece uma imensa heterogeneidade neste universo, delimitando vários estilos de vida. Por outro lado, propõe-se a discutir até que ponto o uso de tóxicos cria elementos de identidade dentro do grupo e lugares perante a sociedade.

O primeiro grupo é definido como uma "roda intel ectual-artístico-boêmia". Nesse universo amplo, Velho identificará três vertentes que expressariam visões de mundo distintas, as quais ele classifica como "esquerdista", "boêmia" e "vanguardista aristocratizante". Seu grupo de investigação etnográfica será este último. A caracterização deste grupo desenha o ethos e estilos de vida de um setor das camadas médias cariocas de zona sul da época (com surpreendente atualidade em alguns aspectos). Com o passar dos dois anos, Velho percebeu uma tendência à diminuição do caráter, outrora mais evidente, de contestação e conflito familiar, caminhando para uma vinculação de dependência econômica e conformismo. Tais observações permitiram ao autor enumerar seis características afetivas e cognitivas identificadoras desse grupo: 1) referência central ao indivíduo, sua biografia e originalidade; 2) forte competição; 3) ambigüidade entre a busca de prazer e os esforços e re- 
núncias para obter os recursos econômicos necessários; 4) oscilação entre uma rigidez de desempenho de papéis sexuais e uma pretensa igualdade entre homens e mulheres; 5) constante referência ao tema da mudança nos mais distintos contextos (trabalho, projeto de vida, amizade, relações amorosas, etc.); 6) acentuada ansiedade decorrente desta perspectiva individualista, aliada às cobranças de criatividade e mudanças, de ser autêntico e ao mesmo tempo 'educado e fino'.

O autor aponta que havia entre esses indivíduos uma experiência comum de pertencer a famílias com uma certa 'cultura de berço' e que ascenderam socialmente nas últimas gerações (especialmente pós-64). Essa origem e a luta pela manutenção desse status, sugere o autor, poderia ser a base para a constituição de uma visão de mundo e de um ethos comum.

O uso dos tóxicos é enfatizado no capítulo 3, quando o autor remonta a trajetória do grupo na experimentação com as drogas: do álcool, maconha, cocaína ao ácido. Relata os distintos padrões de uso associados a cada tóxico, sejam aqueles vistos pelo grupo como socializadores (a maconha), ou como individualistas (a cocaína). Sua narrativa traz as ambigüidades dos valores de afirmação do grupo, oscilando entre a positividade do uso do tóxico como meio de autoconhecimento e mudança, à estigmatização da figura do dependente, do 'viciado'. A opção por determinado tipo de droga e a freqüência de seu uso constituíam uma fronteira, um campo de desvio para o próprio grupo. Velho percebe uma hierarquia de valores que regulava o uso e a escolha do tóxico. Assim, fumar maconha 'abria a cabeça', experimentar ou usar socialmente cocaína ou ácido eram experiências, até certo ponto, necessárias ao autoconhecimento, à afirmação de uma autenticidade e vanguarda. Contudo, o uso de tóxicos era malvisto se abalasse outras referências constituidoras do ethos do grupo, tais como ter uma boa vida, dispor de recursos para viajar e freqüentar lugares sofisticados, 'não perder a linha', etc. Havia, portanto, um controle social interno e uma atribuição de desvio, hierarquicamente construída: do ‘doidão' (ainda com certo charme) ao viciado e doente.

A visão política desse grupo se desenhou a partir de algumas experiências de participação na chamada esquerda até os anos de 64 e foi marcada por um crescente abandono dessa militância pós-golpe (uma fase 'superada' nas suas biografias). Um grande desencantamento com o discurso político revolucionário e com as práticas da esquerda (vistos como autoritários e maniqueístas), associado ao medo concreto de repressão militar teriam forjado nesse grupo um desinteresse ativo pela participação política (com maior ou menor grau de culpa). Em contrapartida, percebeu-se uma valorização da identidade com o discurso artístico e das 'revoluções individuais', feitas pelas mudanças de cada indivíduo em sua própria vida.

Os adolescentes do segundo grupo, também identificados como tendo a mesma origem familiar e social dos vanguardistas-aristocratizantes, tinham interesses próprios à sua geração, tais como o surf, música pop americana, praia e shows de rock. Seu envolvimento com o consumo de tóxicos, geralmente a maconha, era mais intenso e demarcava o reconhecimento de seus semelhantes, funcionando como elemento diferenciador dos 'caretas'. Como dependiam de mesadas, o acesso a tóxicos mais caros, como cocaína, era dificultado (além da desconfiança que sentiam sobre seus possíveis efeitos). Naturalmente, o medo de tóxicos que gerariam descontrole físico e verbal, tal qual o mandrix (citado como de uso do grupo), produzia uma atitude de controle do grupo em relação ao seu uso, caso contrário 'daria bandeira'.

Este grupo, como o dos adultos, revelou limites bem demarcados em relação a um suposto comunitarismo no interagir com outros grupos ou indivíduos consumidores de tóxicos. Assim, as ocasiões de provável 'mistura' com outros jovens de zona norte foram evitadas, revelando uma percepção classificatória e seletiva entre 'nós' e os 'outros' (baseada, sobretudo, no fato de se pertencer a estratos sociais). O uso grupal de tóxicos geralmente se dava em ocasiões como as festas ou em espaços públicos, como as praias e os points.

O ethos e o eidos deste grupo se expressariam na valorização do corpo, na desvalorização da verbalização, na preocupação com a estética como atributo erótico-sensual, na intensa experimentação sexual grupal, definidos num hedonismo vivenciado a partir do sexo, tóxicos e esportes.

O caráter 'desviante' desses jovens revelar-se-ia numa forte repulsa a uma moral de produtividade, seja no universo do trabalho, seja no universo escolar. Estariam basicamente orientados para o prazer, sem culpas, negando-se a quaisquer estruturas de rotina ou de ordem. Tal 'desvio' era, via de regra, fonte de intenso conflito familiar. A perspectiva de frustração das expectativas familiares poderia até mesmo desencadear atitudes rigorosas, como a internação em clínicas psiquiátricas. O 'desvio' poderia ser, em última instância, tratado como doença.

A forte pressão familiar e a 'semiclandestinidade' desses jovens reforçava a importância do grupo em suas vidas.

O conhecimento político deste grupo era de desinformação e desinteresse generalizados. Por serem mais jovens, não havia quaisquer citações em participações políticas na década de 60, ou mesmo na de 70 . Desfrutavam a política do 'viva e deixe viver', procurando não polemizar, desfrutando a vida sem desgastes. Por outro lado, achavam uma total 'caretice' a vida militar e tinham horror à polícia. Desenvolveram, inclusive, estratégias de reconhecimento e evitação à repressão policial.

Comparativamente, esses dois grupos pertenceriam a um grupo de status comum (aristocracia de estratos médios), que se apoiava numa situação econômica privilegiada e códigos específicos de prestígio e honra social. Embora partilhassem de ethos diferenciados, Velho defende a existência de pontos de contato entre ambos, tais como o uso de tóxicos e um "desvio em relação à cultura dominante".

Ainda que na conclusão e em algumas outras citações no corpo do livro o autor busque relativizar a atribuição social de desviante aos indivíduos do grupo de adultos, esta ênfase se esvanece quando, em muitas ocasiões, reconhece o caráter gradativamente mais conservador desses indivíduos aos padrões familiares de origem (referência à própria atribuição de desvio). Se a ancoragem do desvio é pela negação a uma moral dominante de produtividade, tais indivíduos demonstraram ter vários outros recursos (de status e financeiros provenientes de doações familia- 
res), que os indulgenciavam a uma cobrança mais rigorosa do desempenho social. Por outro lado, o texto ganha força quando investe no universo dos adolescentes, mais claramente identificados pelas famílias e pela sociedade geral como 'desviantes'. Ao contrário do primeiro grupo, o uso de tóxicos é elemento fundamental para a constituição de uma identidade grupal e definidor de sua situação desviante. Contudo, também dispõem de recursos de status para evitar uma pressão mais violenta em relação ao seu comportamento desviante. Além disso, a situação de adolescente colocava-os num campo ambíguo, entre receber complacências, pois é 'uma fase que passa', e já indiciar frustrações às expectativas de desempenho geradas por sua família, desencadeando punições severas para corrigir a tempo o comportamento 'marginal'.

O livro de Velho, além de ser uma leitura extremamente agradável, é um documento precioso para o estudo dos estilos de vida das denominadas 'camadas médias'. Embora referenciado a um período determinado, seu trabalho não pode ser considerado datado, ainda que constitua valioso testemunho histórico. Sem dúvida, os ethos descritos provavelmente se diferenciaram ao longo das muitas transformações ocorridas nestes últimos 24 anos. Mas o convite feito por Velho ao aprofundamento deste universo complexo das 'camadas médias' traduz um desafio à interpretação etnográfica e uma pista ao quadro de vaIores e motivações da 'elite' acadêmica e intelectual carioca, quiçá brasileira.

Contudo, ao se centrar na categoria 'desvio', o texto revela a sua vinculação com a tradição acadêmica dos anos 70. Portanto, a sua leitura convida a uma reflexão sobre a atualidade dessa categoria e ao que ela remete, seja na tradição das ciências sociais, seja na realidade dos anos 90 .

Suely F. Deslandes Instituto Fernandes Figueira/

Centro Latino-Americano de Estudos deViolência em Saúde Fundação Oswaldo Cruz

Rio de Janeiro, RJ, Brasil
ÉTICA E SAÚDE: QUESTÕES ÉTICAS, DEONTOLÓGICAS E LEGAIS, TOMADA DE DECISÕES, AUTONOMIA E DIREITOS DO PACIENTE, ESTUDO DE CASOS. Paulo Antonio de Carvalho Fortes, São Paulo: Editora Pedagógica e Universitária. 520 pp.

ISBN 85-12480-300

O livro Ética e Saúde, de Paulo Antônio de Carvalho Fortes, publicado pela Editora Pedagógica e Universitária (E.P.U.), propõe-se a orientar estudantes e profissionais de saúde a respeito de questões éticas, deontológicas e legais que se apresentam na prática dos serviços de saúde. A crescente desumanização da assistência à saúde é uma constatação abordada inicialmente pelo autor e justifica a atualidade do tema e da iniciativa de divulgá-lo entre aqueles que são ou serão os responsáveis pelas ações de saúde no cotidiano dos serviços.

Apesar de a saúde ser um direito constitucional formal, as políticas econômicas e sociais do País não o concretizam efetivamente. Especialmente as instituições de assistência à saúde vinculadas ao Sistema Ú nico de Saúde (SUS) são palco de constantes situações de desrespeito à dignidade humana. No capítulo 1 , são assinalados exemplos, como a morte de pessoas com problemas renais crônicos em Caruaru, de idosos na Clínica Santa Genoveva no Rio de Janeiro, de recém-nascidos nas maternidades em Rondônia e também no Rio de Janeiro. Estas foram ocorrências escandalosas, divulgadas pelos meios de comunicação, que sinalizaram como o descaso e negligência com a vida são moeda corrente nos serviços de saúde.

As precárias condições materiais da assistência, os baixos salários, explicam apenas em parte e não justificam de modo algum a crueza com que pessoas doentes são tratadas cotidianamente. Coloca-se a necessidade de transformar a cultura prevalente entre os profissionais de saúde no sentido de serem adotados princípios éticos que reconheçam os direitos dos pacientes e contribuam para viabilizar a humanização da assistência à saúde. Esses princípios éticos, porém, são da responsabilidade pessoal de cada profissional ou devem ser impostos através de normas? Como é definida neste sentido a ética?

É necessário, portanto, ressaltar a distinção entre o conceito de ética e o de moral. A moral é um conjunto de princípios e valores que normatizam a conduta dos homens em suas relações sociais em um dado momento da História. Já a ética implica opção individual ativa, adesão íntima a valores, estando ligada intrinsecamente ao conceito de autonomia. A ética não é imposta do exterior e sim interna a cada sujeito. Dada a extrema diversidade e relatividade das possibilidades de opções éticas, o autor interroga a necessidade de definir quais os parâmetros objetivos que circunscrevem os significados práticos do estabelecimento de limites e exigências éticas. Dessa maneira, na seqüência do capítulo 2 , o texto trata a ética na sua relação com normas jurídicas e deontológicas, mais relacionadas ao conceito de moral do que propriamente ao de ética: leis, regulamentos e conjunto de normas que definem o comportamento dos membros de um grupo profissional os códigos de ética e as teorias de tomada de decisão ética por parte dos profissionais. 
O terceiro capítulo refere-se à autonomia, do ponto de vista do direito dos pacientes à liberdade de escolha na relação com os profissionais e serviços de saúde. Autonomia é outro conceito complexo, pois trata de uma questão em que o conflito é intrínseco: a idéia de autonomia não pode estar dissociada da de responsabilidade. Os interesses individuais não podem ser pensados desarticulados dos do coletivo. Quais os limites da autonomia? "Respeitar a pessoa autônoma pressupõe a aceitação do pluralismo éticosocial, característico de nosso tempo; é reconhecer que cada pessoa possui pontos de vista e expectativas próprias quanto a seu destino, eque é ela quem deve deliberar etomar deci sões seguindo seu próprio plano de vida e de ação, embasada em crenças, aspirações evalores próprios, mesmo quando estes divirjam dos valores dos profissionais de saúde ou dos dominantes na sociedade". Porém, especificamente na assistência à saúde, é difícil avaliar a competência de uma pessoa doente para tomar decisões autônomas em determinadas situações. $O$ autor exemplifica discutindo casos de indivíduos que sofrem distúrbios mentais, ou redução transitória da capacidade de autonomia. Como se colocam os limites da autonomia no caso específico dos adolescentes? O que caracteriza uma conduta paternalista? A apresentação das questões através de estudos de casos facilita a discussão de problemas concretos que aparecem no cotidiano dos serviços de saúde.

Outro aspecto abordado no capítulo 3 é o direito de a pessoa consentir ou recusar o que lhe é proposto em termos de ações preventivas e ou curativas. $\mathrm{O}$ consentimento deve ser esclarecido, isto é, requer informações adequadas para que os procedimentos sejam bem compreendidos. O direito à informação, como base de fundamentação de decisões autônomas, é o tema abordado no capítulo 4 . A característica ética da informação pressupõe fornecê-la em padrões acessíveis à compreensão dos pacientes, no que se refere tanto aos objetivos e natureza dos procedimentos, quanto a seus inconvenientes, riscos e conseqüências. Diferenças sociais e culturais se expressam na linguagem utilizada por profissionais de saúde e seus pacientes. Entre fornecer informação e fazê-lo segundo a necessidade e características das pessoas que vão utilizá-la, há uma importante distância. Ultrapassar esta distância depende de um movimento ativo que demanda a atitude ética de cada profissional.

Ainda no capítulo 4, são analisadas as características e importância do prontuário médico como espaço oficial de registro de informações a respeito dos cuidados prestados ao paciente. Já o direito à privacidade da informação é trabalhada no capítulo seguinte. Como se configura o segredo profissional como respeito ao direito à privacidade? $\mathrm{E}$ a violação deste segredo como infração legal? Em que casos a quebra de sigilo se justifica ética e legalmente? Qual o papel da administração dos serviços na garantia da privacidade dos pacientes? Além dessas questões, este capítulo fala sobre a garantia de sigilo na organização de sistemas crescentemente informatizados e sobre as questões deontológicas vinculadas ao segredo.

O direito ao socorro nas situações de risco iminente de vida é tratado em seguida, no capítulo 6 . As situações que caracterizam omissão de socorro são definidas e trabalhadas com base em estudos de ca- sos. A falta de vagas em um hospital não justifica a recusa em prestar assistência a alguém em perigo iminente; a demora em atender um pessoa em estado grave pode equivaler à omissão de socorro. O capítulo 7 se refere à liberdade de ir e vir o direito à livre locomoção. Uma situação freqüente no cotidiano dos serviços são as altas a pedido dos pacientes, contrárias a sua avaliação clínica. Como considerar em cada caso o que configura um atentado à liberdade de locomoção ou, interpretando de outra forma, uma omissão de socorro?

Finalmente, no oitavo e último capítulo, o livro aborda a questão da ética nas pesquisas em seres humanos. Tais pesquisas se justificam pelo princípio da beneficência, que objetiva aumentar o bem-estar do ser humano. Porém, esta é historicamente uma das áreas que envolve dilemas éticos dos mais controvertidos. O autor faz um histórico dos documentos que buscaram regulamentar normas éticas para realização de pesquisas em seres humanos, classifica os tipos de pesquisa segundo o interesse ou benefício para o pesquisado e apresenta os princípios éticos que orientam as atividades de pesquisa. A eqüidade na distribuição dos resultados, o respeito à autonomia das pessoas pesquisadas, a consideração não só da beneficência, mas também da não-maleficência das intervenções durante a pesquisa, as normas deontológicas na realização de pesquisas são itens abordados neste capítulo.

O livro sistematiza, assim, de forma clara e simples, informações sobre questões, procedimentos e normas éticas para estudantes e profissionais de saúde. Para além dessa contribuição, cabe a todos nós envolvidos com a pesquisa e formação de recursos humanos para saúde aprofundarmos a reflexão sobre como viabilizar a construção da autonomia e responsabilidade dos profissionais, reforçando ao mesmo tempo a dos sujeitos (pacientes) envolvidos na relação com os serviços de saúde.

\section{Dina Czeresnia}

Departamento de Epidemiologia Métodos Quantitativos em Saúde Escola Nacional de Saúde Pública Fundação Oswaldo Cruz Rio de Janeiro, RJ, Brasil 
SYSTEMATIC DATABASE OF DIPTERA OF THE AMERICAS SOUTH OF THE UNITED STATES (FAMILY CULICIDAE). J osé Henrique Guimarães. São Paulo: Plêiade/Fapesp, 1997. 286 pp.

Ao efetuarmos uma rápida revisão em alguns livros de parasitologia, iremos deparar com uma gama de doenças transmitidas por vetores, sendo a maioria destes constituída por insetos pertencentes à ordem Diptera. Aí encontram-se importantes vetores de doenças de grande impacto social e econômico, tais como: filariose, dengue e malária. Porém, esses três exemplos de parasitoses não foram dados por acaso. Seus vetores Culex quinquefastiatus, Aedes aegypti e Anopheles spp., respectivamente, estão classificados na família Culicidae, que, possivelmente, constitui o grupo de dípteros com o maior número de espécies de interesse epidemiológico.

O livro de José H. Guimarães aborda justamente esse grupo, trazendo uma grande contribuição para a pesquisa biológica sobre os culicídeos. A obra em questão, sistemática, um catálogo bibliográfico em biologia, traz dados fundamentais para a localização de informações sobre culicídeos neotropicais.

Na primeira parte do livro, encontra-se um breve comentário sobre a situação e organização desse taxon. Assim, o autor relata o reconhecimento e organização das subfamílias Anophelinae, Toxorhynchitinae e Culicinae, com suas respectivas tribos, gêneros e subgêneros, além de 13 gêneros de distribuição exclusivamente neotropical. Logo após, há uma relação de referências bibliográficas sobre Culicidae, organizadas por assuntos: biologia, morfologia, taxonomia, publicações gerais de países das Américas do Sul e Central, bem como catálogos, checklists e estudos regionais.

Já de início, o leitor encontrará referências que podem ser de extrema utilidade para seu estudo. Contudo, o interesse de quem estiver consultando o catálogo pode ser mais específico, como, por exemplo, a espécie Aedes aegypti, devendo, então, passar para a segunda parte do livro, onde encontrará, após busca no índice remissivo, uma gama de referências sobre a subfamília, gênero, subgênero e espécie. Tais referências podem ser relativas à distribuição, taxonomia, biologia, revisão, validação do nome e genéti$\mathrm{ca}$, dentre outras. Na verdade, as referências da primeira e segunda partes do livro, sobre as quais comentamos aqui, são citações (autor e ano), encontradas no final do catálogo juntamente com as referências completas das publicações mais importantes para sua pesquisa.

Além do extenso levantamento bibliográfico, o autor teve o cuidado de incluir um glossário de abreviações utilizadas, facilitando a utilização do catálogo e auxiliando o pesquisador a se familiarizar com a nomenclatura.

De acordo com o exposto, o livro de J. H. Guimarães é uma importante referência para aqueles que estão realizando ou que irão realizar pesquisa sobre culicídeos. Apesar de, atualmente, existirem outras possibilidades de se efetuarem levantamentos bibliográficos, seja consultando bases de dados informatizadas, seja em catál ogos eletrônicos de bibliotecas, esse livro não deve ser descartado. Ainda que as novas formas de acesso nos permitam encontrar, com grande facilidade, os mais recentes artigos publica- dos, o livro de J. H. Guimarães inclui uma relação de trabalhos, muitos dos quais considerados clássicos, não só de décadas anteriores, mas também do século passado, que não são encontrados nas modernas bases de dados.

Infelizmente, a qualidade gráfica desse importante trabalho fica a desejar. O leitor irá defrontar-se com um livro cuja qualidade de impressão varia entre as páginas, estando algumas extremamente claras, além encontrar páginas coladas e com cortes errados. Outrossim, o livro não possui ISBN (International Standard Book Number), número essencial que informa o país, editora, título e outras identificações sobre a obra, facilitando o acesso à publicação. Apesar dessas fal has técnicas de impressão e acabamento, a obra é fundamental para os que têm interesse em culicídeos, quer seja voltado para os estudos básicos em biologia e ecologia, ou em áreas aplicadas a epidemiologia e controle de endemias.

Reinaldo S. dos Santos

Departamento de Endemias Samuel Pessoa

Escola Nacional de Saúde Pública

Fundação Oswaldo Cruz

Rio de Janeiro, RJ, Brasil 